\title{
ASSESSING THE READINESS FOR CLOUd COMPUTING IN HIGHER EDUCATION INSTITUTIONS IN THE KINGDOM OF BAHRAIN: TOWARDS AN EDUCATION CLOUD COMPUTING STRATEGY
}

\author{
Jaflah Al-Ammary and Zakaria Saleh \\ Department of Information Systems, University of Bahrain, Sukhair, \\ Kingdom of Bahrain
}

\begin{abstract}
There is a great potential for cloud computing adoption in Bahrain, something which will power exciting innovations and touch every area of people's lives, especially in the education sector. The current study investigates the critical success factors for implementing cloud computing into learning activities in higher institutions in Bahrain and how can effectively enhance the digital educational environment. The data sample of the current research consists of academic and administrative staff from nine universities in Bahrain, both private and public universities. The findings revealed that the adoption of cloud computing has proven to help build a digital educational environment in the Kingdom of Bahrain. Cloud computing can help in making digital research and digital learning and teaching. Besides offering more excellent student choices in education, cloud computing can provide good opportunities for enhancing research in these universities.
\end{abstract}

\section{KEYWORDS}

Digital learning environment, Digital research, Privacy and security, Competitive pressure, Governess and policies, and Organizational readiness

\section{INTRODUCTION}

Cloud computing emerges as one of the hottest topics in the IT industry and education. It simplifies the usage of computing resources in the same way as effective services of water and electricity. The Cloud computing environment provides more cheap, flexible, and available computing resources. Still, it has transformed how educational institutions conduct their activities and has added value to the computing services and operational management [1]. Various scholars have defined this technology. According to the National Institute of Standards and Technology [2], "Cloud computing is a model for enabling convenient, on-demand network access to a shared pool of configurable computing resources (e.g., networks, servers, storage, applications, and services) that can be rapidly provisioned and released with minimal management effort or service provider interaction."

Research has proven that cloud computing has drastically changed how various activities are being conducted and has increased an organization's scalability, and also made virtualizing resources on the Internet more feasible [3][4][5]. It has become evident that cloud computing is being highly integrated with various industries, including education [7]. The integration of cloud 
computing in education is relatively new, though, and it is expected to impact learning processes substantially.

According to Ercan [7], information and communications technology (ICT) such as cloud computing have become necessary to guarantee the effectiveness of learning platforms of educational institutions worldwide. Applying a pay-as-you-go model, Ercan [7] suggested using cloud computing to create a model that combines computing resources (processors, memory, storage, bandwidth, and so on) and made it available for students, teachers, and administrative staff in educational institutions so that the infrastructure is scaled up or down as per the requirement of the user.

Another cloud model, called "BlueSky," was designed by Dong et al. [8] (2009). This model embraced cloud computing for e-learning. The researchers assert three qualities of the model: dependability, scalability, and low-cost structure, and these three facilitate implementing this model in educational institutions. BlueSky model aims at providing an e-learning structure that integrates conventional processes (data collection, load balancing, etc.) with cloud computing so that the offered learning tools are virtual and made available on demand. Another e-learning model that was called "Education and Learning as a Service" (ELaaS) was proposed by Madan et al. [9] and was also based on cloud computing, and this model offers access to resources and services on a rental basis, something which should make using these resources more costeffective for both learners and educators. Muhammad and Abdulrahman [10] proposed a model that is more rigorous than some popular e-learning platform such as Blackboard. The proposed model is learner-centred rather than content-centred. This model is learner-focused rather than content-focused, and it integrates cloud computing with learning processes.

Internationally, education has remained broadly the same for the major part of the 20th century. In the new digital and knowledge society of the 21 st century, the traditional ways of learning (learn through memorization and recitation techniques) can present a barrier for the new innovative ways of learning. The advancement in ICT, has greatly influenced teaching and learning. With the help of ICT, knowledge can be acquired through video clips, audio sounds, and visual presentation besides the printed materials, which can help in transforming the teaching environment into a learner-centered one [11].

Educational transformation and reform have become an urgent issue worldwide to meet the demands of new educational objectives, and Bahrain is no exception. Due to cloud computing technologies' ability to change the way applications are developed and accessed, cloud computing's attractiveness in electronic learning (e-learning) is growing, and an e-learning system based on cloud computing infrastructure has become feasible [12]. According to Anjali and Pandey [13], in higher education, cloud computing is practical and can increase the quality of education by providing educational institution access to global resources over the Internet for data analysis and data storage. They suggest that the lecturers focus on creating content so that students can understand and share ideas. Through access to a wide range of resources, cloud computing can improve students' academic performance. Studies related to cloud computing have focused heavily on the theoretical definitions of clouds and studying the technical side, while less attention has been given to user acceptance of this emergent tech. In contrast, In an effort to fill this gap in the literature, this paper presents a study iToers' acceptance of cloud computing.

This study investigates the critical success factors for implementing cloud computing into the learning activities in higher institutions in the Kingdom of Bahrain, and how this technology can be effectively applied to enhance learning activities. It does so by listing the major factors 
influencing the adaption of the process of cloud computing in the educational system from three dimensions: technological, organizational, and environmental. The study also explores the impact of cloud computing adoption in enhancing digital educational environment, which includes both digital research and digital learning and teaching environment.

The current study is articulated into five sections, including the introduction. The next section highlights the research background by discussing the potential cloud computing development by higher education in the Kingdom of Bahrain. Research model and hypotheses are discussed in the third section. The research method and data collection are discussed in the fourth section. In the fifth section, the data analysis and results are presented. The final section presents the discussion and conclusion of the study.

\section{Potential Cloud Computing Deployment by Higher Education IN KINGDOM OF BAHRAIN}

The Kingdom of Bahrain was the first Arab country to take an initiative to adopt the cloud computing policy [14]. Carlson [15], the Vice President of Worldwide Public Sector of Amazon Web Services, believes that the Bahraini government is one of the most forward-thinking in the Middle East and that there is great potential for cloud computing adoption in Bahrain, which will power exciting innovations and touch every area of people's lives, both in Bahrain and around the world. As the demand for access to higher education in Bahrain on the one hand and the need for more effective skills and abilities on the other are growing, innovative and cost-effective solutions can be provided by education technology (EdTech) in such a way that it will shape future knowledge economy [16]. The strategy of higher education in Bahrain focuses on Public and Private Partnership (PPP) as one of its main areas of focus in an attempt to develop a PPP national EdTech portal and cloud infrastructure for public [16].

At the institutional level, could computing can be beneficial in cooperative learning and collaborative methods of instructions [17]. For example, the University of Bahrain uses cloud computing to store substantial amounts of data in the cloud, and it also incorporates the technology directly into academia, allowing for easier access to learning through the use of software such as One Note, Office 365, and Google Docs, all of which directly promotes a "collaborative culture" between students and instructors [18].

The use of cloud computing in institutions of higher learning can provide many benefits to universities and colleges. Cloud Computing emerges as a likely platform to support e-Learning systems by implementing data mining techniques to work in a distributed situation for exploring the vast amount of discussions to extract the inherent knowledge [19]. Through courses and hands-on lab training, the University of Bahrain students can use the self-service business intelligence (BI) service built into Excel and Office 365 to derive patterns and trends that exist in complex data and generate rich summaries for presentation and for business analytics. According to Bittman [6], even though cloud computing can offer colleges and universities flexibility, scalability, and on-demand recourses, cloud computing colleges and universities' adoption is lower than anticipated. However, while there are several obstacles to implementation regarding security and data integrity, institutions are working together and are jointly resolving these challenges [20]. Nevertheless, the benefits of cloud computing and the risks and limitations of using it by an institution need to be analyzed. Based on this analysis, a model of cloud computing may be chosen to be used to suit the institution's needs and strategies. 


\section{RESEARCH MODEL AND HYPOTHESES}

The adoption model for the factors impacting cloud computing adoption has been based on a massive review of the previous literature and previous studies on cloud computing. The literature review has revealed that Technology Acceptance Model (TAM) has been used enormously in examining the adoption of cloud computing. However, different external factors were identified by adopting both Technology, Organizational and Environmental (TOE) based model or/and Diffusion of Innovation (DOI) - attribute or characteristic of technology innovation [21]. While a considerable number of studies examine the structural perspective of cloud computing adaption, not many shed the light on the impact of the adaption of this technology. Therefore, this study adopts a holistic cause-effect based model. The cause-side of the model examines the factors that impact the adoption of cloud computing. A framework was extracted from the TOE framework and integrated with the DOI theory to examine the model's cause side. On the other hand, the effect side of the model examines the effect of adopting cloud computing in enhancing a digital educational environment by building both digital learning and digital research environment in the educational institutions in the Kingdom of Bahrain as depicted in Figure (1).

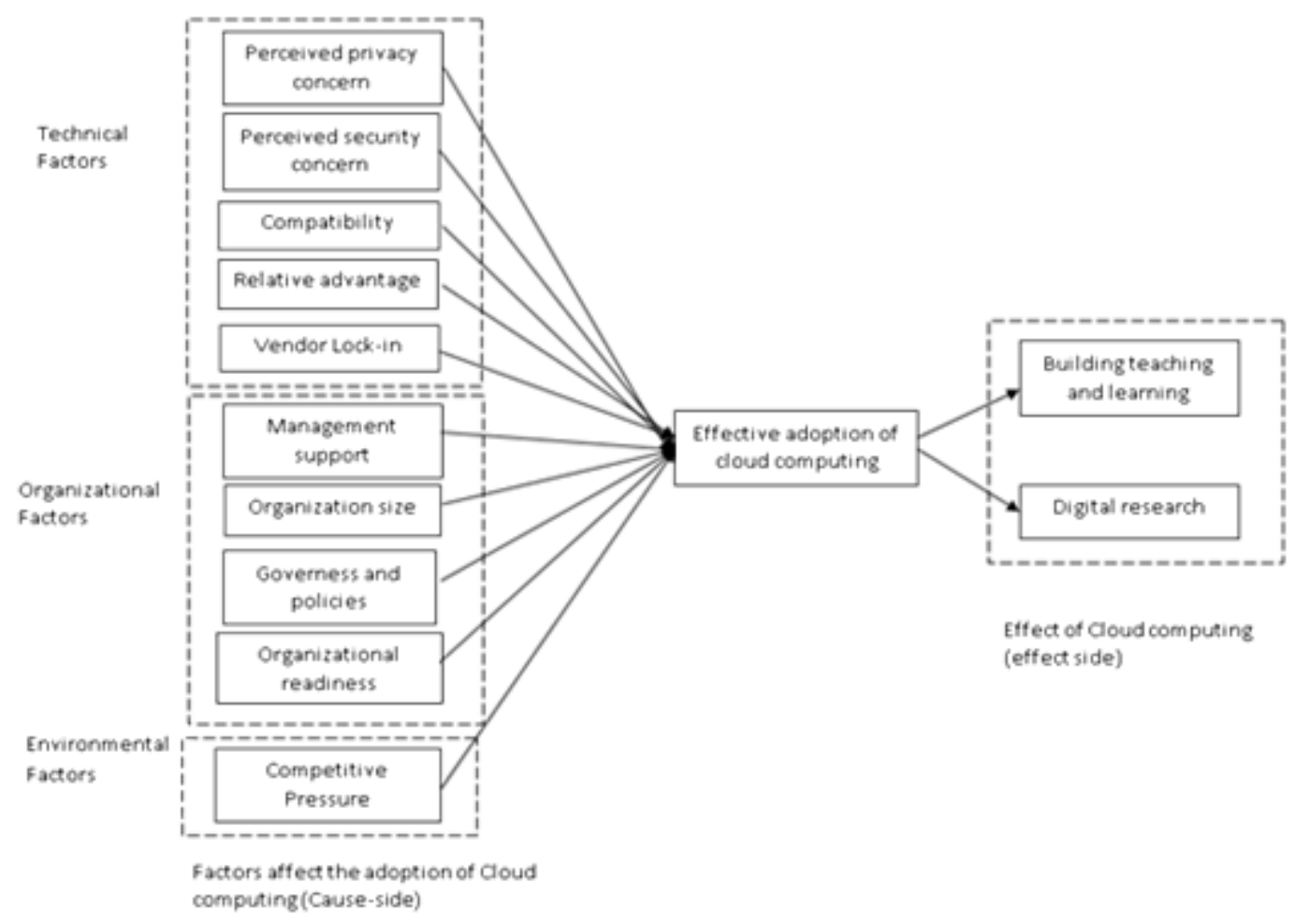

Figure 1: Research Model

\subsection{Cause Side: Factors Affecting the Adoption of Effective Cloud Computing in the Kingdom of Bahrain}

\subsubsection{Technological Factors}

Relative advantage is defined as the degree to which a technological factor is perceived as providing greater benefit for firms [21]. It is the degree to which an innovation is perceived as providing more benefits than its predecessor [22][23]. In cloud computing, a relative advantage can be considered the level of benefit to an organization if they decide to move into cloud 
International Journal of Managing Information Technology (IJMIT) Vol.13, No.1, February 2021

computing [24][22]. Implementing and understanding an innovative technology or new system may take users a long time [25], especially that organizations may not have confidence in a cloud computing system because it is relatively new to them [26][25]. Cloud computing offers technical as well as economic advantages over traditional IT environments [23]. Stieningera et al. [27] mentions that some of the major advantages of cloud computing solutions are reducing the load on the network infrastructure, reducing hardware maintenance, increasing collaboration, cutting down cost, making administration easier and more flexible, and increasing automation. Moreover, some expected benefits of embedded cloud computing services include the following: speedy business communications, efficient coordination among firms, better customer communications, and access to market information mobilization [22]. Based on this argument, the following hypothesis was proposed:

\section{H1: Relative advantage has a positive impact on the effective adoption of cloud computing}

Compatibility in the context of cloud computing can be defined as the degree to which cloud computing technologies and applications fit with the organizational values, practices and needs [21][28][24]. The compatibility of a firm's applications with the cloud environment is a real problem that an organization needs to be attentive to when considering the use of the cloud [24]. Firms are more willing to adopt new technologies when these technologies are compatible with available work systems. This is because when they are incompatible, substantial adjustments, which will require a lot of learning [25][29]. Additionally, organizations are more likely to adopt technical innovations that are more compatible with their values and their needs. This compatibility has been found by several studies to positively influence the adaption of technologies [29]. Almubarak [30] asserts that compatibility was one of the most critical factors affecting Saudi hospitals when deciding whether or not to adopt cloud computing. The increase of compatibility influences the implementation intention and the real implementation of cloud computing in a positive direction [31]. Moreover, compatibility with cloud computing will facilitate the cloud computing adoption process [22]. Therefore, the following hypothesis was developed:

\section{H2: Compatibility has a positive impact on the effective adoption of cloud computing}

Security and privacy are major concerns among many institutions of higher education [32]. Previous studies have revealed that security is a very high-risk element for accepting the adoption of cloud computing in an organization [23][31] and is the main concern of the organization, particularly when the data goes out of local organization networks [31]. One indicator of a cloud computing provider's success is the ability of their service to provide effective security protection for an organization's files and data [31]. On the other hand, privacy is one of the recognized risk factors in cloud computing [33].

Cloud computing was initially developed to reduce the use of hardware and allow access to experienced provider to the data to increase privacy and security managing the computing environment by more experienced providers [34]. Despite that, cloud computing still has privacy and security issues, particularly when the provider does not secure full protection for their users' data [34]. This is because the external provider, who is hosting the users' data, may abuse their ability to access this data without the user's authorization or the user's consent [35]. The pass of Customer Privacy Bill of Rights by the US government is one of the laws that aim at creating a risk-free Online; however, there is a still a lot to be done to secure users. Adopting cloud computing by higher educational institutions means the relocation of very critical and sensitive data such as students' records, researchers' patents and intellectual properties outside campus, 
International Journal of Managing Information Technology (IJMIT) Vol.13, No.1, February 2021

making privacy and security the top concerns for adopting cloud computing [36]. Correspondingly, the following hypotheses were proposed:

H3: Security has a positive impact on the effective adoption of cloud computing

H4: Privacy has a positive impact on the effective adoption of cloud computing

Vendor lock-in, which is also called also data lock-in, is the situation where organizations are dependent or locked-in on a single cloud service provider and cannot easily transfer data and programs from one cloud provider to another or in-house [37] without substantial costs, legal constraints, or technical incompatibilities [38]. It refers to the difficulty of switching to other cloud vendors due to cost or technical barriers. Vendor lock-in is a major obstacle to the growth and adaption of cloud computing [38].

When cloud computing services are used, companies become dependent on the provider services and are not able to move applications or data across different cloud services or revert back to inhouse computing [22]. In most cases, the semantics of cloud providers' resources and services do not match with each other, as providers mandate the use of specific IT resources (e.g., database, operating system, hardware), and the cost of switching to another provider is high [22]. One of the risks that user of cloud computing may face is the vulnerability to increased prices (such as subscribing to premium services), reliability problems (such as service outage or latency), and the possibility of providers shutting down the business [38]. This probability of these risks varies from one model to another [38]. For instance, IaaS vendor lock-in has the lowest risk because most vendors use the same virtualization environments, which makes it easier for customers to move between cloud providers [39][38]. However, the highest risk is with SaaS, since the vendor controls all the key components of the customer's system [39]. Based on this, it can be proposed that:

\section{H5: Vendor lock-in has a positive impact on the effective adoption of cloud computing}

\subsubsection{Organizational Factors}

Organizational readiness is the readiness of an organization's financial and technological resources, which indicate the organization's capability to adopt a change or improvement [40]. The organization readiness can also encompass more than only financial and technological readiness. Ramdani et al. [40] and Alhammadi et al. [23] add to these two human and technological resources as a requirement to measure the readiness to adapt could computing. Alhammadi et al., [23] stresses the importance of knowledge, experience and skills on the cloud computing as factors reflecting organizational readiness.

Organizational readiness has two sub-constructs: financial readiness and technological readiness. Financial readiness refers to the resources needed for technology implementation of cloud computing and other possible after-implementation costs [23]. However, the technological readiness of organizations, meaning technological infrastructure, influences the adoption of new technology [41][42][43] as well as the IT human resources who provide the knowledge and skills to implement cloud-computing-related IT applications [43][25]. IT human resources provide the knowledge and skills to implement cloud-computing-related IT applications [43]. The adoption of modern technology is impacted by the technological readiness of organizations [44]. Cloudcomputing-associated IT applications require IT human recourses to be well-informed and have good experience to implement these applications in an organization [25]. Accordingly, the more sophisticated IT systems and technical efficiency are, the more capable and confident an 
organization can be about implementing cloud computing [29][25]. With consideration borne in mind, the following hypothesis was proposed:

\section{H6: Organizational readiness has a positive impact on the adoption of effective cloud computing}

Top management is considered a main factor affecting the adaption of cloud computing. Top management support refers to the decision-makers in an organization whose stance affects the adoption of innovation [23], which includes goal specificity, resource management commitment. The complexity and sophistication of technologies necessitate the top management's involvement and support in adopting the innovative technology for supporting business needs [44]. Top management support is considered in many studies as an important factor influencing the adoption of technology innovation [23], and this is achieved by creating a supportive environment and securing suitable and sufficient resources, and supporting these two steps with a clear vision and with commitment [43][25].

With regard to cloud computing, top-management support plays a significant role in the adoption of cloud computing as it involves the provision and integration of several of resources and reengineering of procedures [44]. However, top management needs to understand the businessrelated benefits of cloud computing and its efficient and effective impact to support the implementation of such a project [44]. Top management support is a major challenge to adopting cloud computing as this support is the only way financial and technological support is made possible. Alyssa et al. [45] confirms that the capacities of top management is an important factor for the success of implementing cloud computing in Saudi Arabia, since the top management is the driving force that can shift from conventional systems to could computing system. Since the support of the top management in an educational institution is perceived to be one of the main factors that will accelerate the adoption of cloud computing, the following hypotheses were proposed:

H7: Top-management support has a positive impact on the adoption of effective cloud computing in the Kingdom of Bahrain

An organization or firm size is defined by the number of employees, the amount of investments, the target market and the annual revenue [24]. Low e al. [25] suggests that firm size impacts how an organization would perceive the strategic importance of cloud computing and technological advancements. It is a crucial determinant that will ensure cloud computing adoption as a technological innovation [25]. A number of studies confirm that the size of an organization is a major determinant of IT solutions being adopted or rejected by the organization [42][24][29]. Large firms have been found to adopt more IT innovations due to their flexibility and ability to undertake risks [42][43]. Larger firms are more likely to be more flexible in their resources whether technological, financial or human- and hence more likely to adopt emergent technologies [25]. The larger an organization is, the more capable it becomes to take greater IT-related risks adoption [46][23]. This is because bigger organizations have more resources and experience in the field and have greater technical innovations than do smaller organizations. Studies have shown that smaller firms do not willingly accept newer technologies, although they are more adaptable [46][23]. The size-determinant also applies to the public sector. Another perspective of the organizational size is that public-sector organizations are no different and their bigger size can also lead them to incur failures [44]. The discussion mentioned above gives a possible reason for that. There is a substantial positive relationship between organizational size and IT acceptance and adoption and, therefore, the following hypothesis was developed: 
H8: Organizational size positively impacts adopting a practical cloud computing in the Kingdom of Bahrain.

Governance and policies related to IT strongly affect how resources of innovative technologies are developed, supported, and provided. This process may involve the integration of resource and re-engineering of the business model. These issues include audit to process management, IT governance, regulatory compliance, IT security, and accountability for access management, ediscovery and privacy and protection of research results [47]. It is basically how well the policies and rules should be implemented to ensure the smoothness in an organization's operation. [47]. The loss of governance and compliance risks is identified as key factors to consider when developing a regulatory policy environment for cloud computing. Governance involved the management of tactical, operational, and strategic models that defines the way organizations structure to establish their goals, make decisions and allocate resources.57. Part of the organizational governance is IT governance, which is essential in enhancing performance, confidentiality, risk management, strategies and resources [45]. Usually, IT governance takes care of IT assets, ensuring approved running of all hardware systems, processes etc., as per the company's policies and procedures. IT governance looks after the maintenance and control of available assets and ensures that these assets contribute to its business strategy and goals [47]. Organization governance influences its adoption of electronic business and institutionalization. Organization Governance influences its adoption of electronic business and institutionalization [45]. A study by Chang, 60 suggests that organizations need to clear up the roles and responsibilities before migration to cloud adoption [31]. Chang et al. [1] asserts that the loss of governance and control over resources might lead to unclear roles and responsibilities. Therefore, the following hypothesis was developed:

H9: Governance and policies have a positive impact in adopting an effective cloud computing in the educational institution

\subsubsection{Environmental Factors}

Competitive pressure is defined as the stress level put on an organization when a competitor adopts a new technology [41]. IT plays a strategic role in sustaining the company's competitive advantage and leading-edge, the implementation and adoption of IT in many companies is perceived to be positively influenced by competition or what is called competitive pressure [25][43]. In a highly competitive industry, an organization encounters pressure from competitors to adopt new technologies. Organizations face pressure and become increasingly aware of and follow their competitors' adoption of new technologies [48]. There is a positive relationship between competitive pressure and the implementation of technological innovations. Thus when a firm implies a new technology, this pushes its competitors to do the same to stay on a par with their [31]. With the emergence of cloud computing, this pressure forces some organizations to adopt cloud computing technology and gain greater benefits, greater operational efficiency, and more accurate data collection [31][48]. Based on this, the following hypothesis was developed:

H10: Competitive pressure has a positive impact on the effective adoption of cloud computing in the Kingdom of Bahrain

\subsection{Effect Side: the Impact of Adopting Effective Cloud Computing on the Educational Institutions in the Kingdom of Bahrain}

The emergence of cloud computing with characteristics such as powerful computing, higher storage, and sharing capabilities, along with high reliability and safety, low cost, and high 
efficiency, has brought new innovative development ideas to education [49]. By applying such concepts in education, cloud computing ensures that learning institutions concentrate more on research and learning than on implementing complex IT infrastructure [31]. Cloud Computing also provides robust and multiple services to the students, faculty, and staff [6]. Cloud computing is playing a vital role in enhancing higher education's effectiveness. It can provide essential gains in offering direct access to a wide range of different academic resources, research applications, and educational tools [50].

On the one hand, cloud computing's high computing power provides new avenues for enhancing higher learning institutions [31]. Cloud computing enables researchers to create groups and conduct collaborative research Online on: on: on: on: on: and increase the efficiency of cooperation and links resources internally and externally. For instance, cloud computing acknowledges the importance of Mobile-learning by which mobile devices are utilized as a way of enriching research through Online on: on: on: on: on: collaboration, something which will ensure sharing information and environment, and hence leading to good quality work and success in research [31]. Moreover, cloud computing has a significant impact on engineering and computer science research. As such, cloud computing is a continuation of distributed models of software development and delivery. It offers new possibilities for software engineering researchers to study multilateral software development [51] and enables the sharing and collaboration of large data with different computational science and engineering research groups [52]. Collaboration becomes more comfortable with IMs (instant messaging) and video conferencing, document sharing and editing of the same document by several people at the same time (via Google Docs) and collaboration (via Skype, Google Chat) is a selling point for researchers to adopt cloud computing [53][51].

On the other hand, cloud computing has brought huge changes to research or community services and as a basic environment and platform for future network learning [54]. Cloud computing has a remarkable effect on changing the teaching and learning process and environment. Cloud computing can be a creative and innovative teaching solution in the 21st century [54] by proving positive effect on the construction of the students' personal learning environment and school resources and the development of the educational information system [49]. By adopting cloud computing, teachers and students will be able to access their individual data using a web browser from a computer or mobile phone from school, home, library, or any other place, ensuring efficient and effective collaboration, communication, and exchange of shared documents. That means students can be mobile while achieving their learning objectives [31].

One of the most popular cloud computing for learning is Google Apps with features including Talk, Mail and Docs, all of which allow collaborative work on writing and editing documents Online on: on: on: on: on:, sharing, uploading and storing in the cloud storage space [54] and, hence enhancing Online on: on: on: on: on: student collaboration and students' learning experience [55][31]. Live@edu is another widespread educational-based cloud computing that ensures that students can access Microsoft products from anywhere without necessarily purchasing them [56]. Cloud computing is also used in the education sector for hosting learning management systems (LMSs) such as Moodle and Blackboard within the cloud. Most institutions outsource the providers of the LMSs due to the high costs involved in the establishment and maintenance of such systems.

Accordingly, the following hypotheses were proposed:

H11: Adopting effective cloud computing has a positive impact on building a digital research environment in the Kingdom of Bahrain 
International Journal of Managing Information Technology (IJMIT) Vol.13, No.1, February 2021

H12: Adopting effective cloud computing has a positive impact on building digital and learning environment in the Kingdom of Bahrain

\section{Research Methodology and Data Collection}

The data sample of the current research consists of academic and administrative staff from all universities in the Kingdom of Bahrain, both private and public universities. Therefore, stratified sampling was used in which two groups were identified: public and private universities. In the Kingdom of Bahrain, there are only two public universities, which are the University of Bahrain (UoB) and Bahrain Polytechnic (BPT), while there are ten private universities. Therefore, the first group consists of UoB and BPT, while the private university group consists of Arab Open University (AOU), the Royal University for Women (RUW), Ahlia University (AU), the Kingdom University (KU), Applied Sciences University (ASU), Arabian Gulf University (AGU) and the Royal College of Surgeons in Ireland (RCSI). The total population for instructors in each university was identified. Furthermore, random samples were selected from each stratum of the population, as shown in Table (1).

Table 1. Sample size and sample distribution Public and private universities

\begin{tabular}{|c|c|c|c|c|c|c|c|c|c|c|}
\hline & \multicolumn{2}{|c|}{ Public } & \multicolumn{7}{|c|}{ PRIVAT } & \multirow[b]{3}{*}{ Total } \\
\hline & UOB & BPT & $\mathrm{AOU}$ & RUW & $\mathrm{AU}$ & $\mathrm{KU}$ & ASU & AMA & RCSI & \\
\hline & \multicolumn{2}{|c|}{966} & \multicolumn{7}{|c|}{371} & \\
\hline Population & 880 & 86 & 25 & 32 & 120 & 28 & 65 & 62 & 39 & 1337 \\
\hline Sample size & 252 & 25 & 7 & 9 & 34 & 8 & 19 & 18 & 11 & 383 \\
\hline
\end{tabular}

A total of four hundred (383) questionnaires were distributed to academic and administrator staff based on the sampling structure using both face-to-face and Online on: on: on: on: on: survey. The survey instruments for this study was developed using validated items from prior studies as shown in Table (2). However, organization size, digital research and digital teaching and learning were adopted for the purpose of the current study.

Table 2. Source for measurement development

\begin{tabular}{|l|l|}
\hline Research Construct & Source for measurements \\
\hline Security and privacy & Pearson, S. (2012) \\
\hline Adoption Intension Relative & (Sultan, N., 2010) \\
\hline $\begin{array}{l}\text { Compatibility } \\
\text { Advantage }\end{array}$ & Moore and Benbasat, 2003) \\
\hline $\begin{array}{l}\text { Organizational } \\
\text { Readiness }\end{array}$ & (Majendran,2013) \\
\hline Top Management Support & (Yigitbasioglu, 2014) \\
\hline Vendor Lock-in & (Peter and Timothy, 2011) \\
\hline Competitive Pressure & (Buyya, et al., 2009). \\
\hline
\end{tabular}

Only two 220 completed questionnaires were returned. The survey instrument provides a response rate of $57 \%$, which can be considered a high rate bearing in mind that many academic and administrative staff, whether from public or private universities, refused to answer the questionnaire either because they were very busy, we're not interested or lacked knowledge on cloud computing. Moreover, many universities refused to respond due to some regulations and policies. 


\section{Data Analysis and Results}

The current section will present information on the participants' demographics, which will provide an indication of the results provided. The results are shown in Table (3) demonstrate that most of the participants were males (65.5\%) from private universities (58.5). Most of the participants were academic staff $(38.9 \%)$ holding PhDs. Degree $(51.5 \%)$ and with almost five years of experience or less.

Table 3: demographics of research participants

\begin{tabular}{|c|c|c|c|}
\hline \multicolumn{2}{|l|}{ Sex } & \multicolumn{2}{|c|}{ Years of experience } \\
\hline Male & $65.5 \%$ & $<=5$ & $26.7 \%$ \\
\hline Female & $35.0 \%$ & 6 to 10 & $14.5 \%$ \\
\hline \multicolumn{2}{|c|}{ Type of educationalinstitution } & 11 to 15 & $21.0 \%$ \\
\hline Public & $41.5 \%$ & 16 to 20 & $20.3 \%$ \\
\hline Private & $58.5 \%$ & $>20$ & $17.5 \%$ \\
\hline \multicolumn{2}{|l|}{ Education } & \multicolumn{2}{|l|}{ Occupation } \\
\hline BSc. or Higher Diploma & $24.5 \%$ & Academic staff & $38.9 \%$ \\
\hline MSc. & $22.0 \%$ & Vice president & $10.1 \%$ \\
\hline PhD. or higher & $51.5 \%$ & Manager or director & $21.3 \%$ \\
\hline Others & $2.0 \%$ & Technician or operators & $29.7 \%$ \\
\hline
\end{tabular}

Table (4) illustrates the results on the awareness and usage of the cloud computing in the universities. The results show that most of the participants were aware about the cloud computing as $78.3 \%$ of them showed that they know what cloud computing exactly was. While only $4.5 \%$ were not aware about the cloud computing (they had no knowledge about cloud computing).

Table 4: Awareness of cloud computing

\begin{tabular}{|c|c|}
\hline Level of awareness on Cloud Computing & \\
\hline I have no Knowledge about Cloud Computing & $4.5 \%$ \\
\hline I know what Cloud Computing is & $78.3 \%$ \\
\hline \multicolumn{2}{|c|}{ Usage of cloud computing } \\
\hline I have some knowledge about Cloud Computing & $16.7 \%$ \\
\hline I'm using cloud computing for personal purpose & $36.7 \%$ \\
\hline $\begin{array}{c}\text { I'm using cloud computing for educational and professional } \\
\text { purpose }\end{array}$ & $43.8 \%$ \\
\hline I never use cloud computing & $19.5 \%$ \\
\hline
\end{tabular}

Moreover, the results show that most of the participants used cloud computing for educational and professional purposes $(43.8 \%)$. While $36.7 \%$ of them used cloud computing for personal purposes, only $19.5 \%$ had never used cloud computing. Table (5) demonstrates different types of cloud computing used by the academic and administrative staff. Most of the participants used the Internet $(98 \%)$, Email (97\%), social media (87\%), and data storage $(65 \%)$. However, a moderate number of them used web hosting (27\%) and remote accessibility (24\%). Figure (2) shows the official adoption of cloud computing by educational institutions. As shown in the figure, only $43.9 \%$ of the educational institutions (private and public) adopted cloud computing, while $24.4 \%$ planned to adopt these technologies in the future. 
International Journal of Managing Information Technology (IJMIT) Vol.13, No.1, February 2021

Table 5: Usage of cloud computing by academic and s administrative staff

\begin{tabular}{|l|r|}
\hline Cloud computing application & \\
\hline Intemet & $98 \%$ \\
\hline Email & $97 \%$ \\
\hline Data storage & $65 \%$ \\
\hline Remote accessibility & $24 \%$ \\
\hline Social Media & $87 \%$ \\
\hline Web hosting & $27 \%$ \\
\hline Software development & $12 \%$ \\
\hline
\end{tabular}

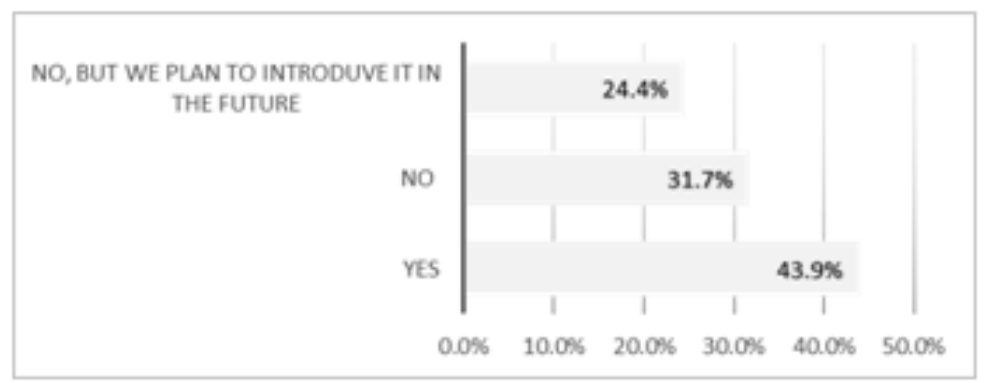

Figure 2: Adoption of cloud computing by educational institutions

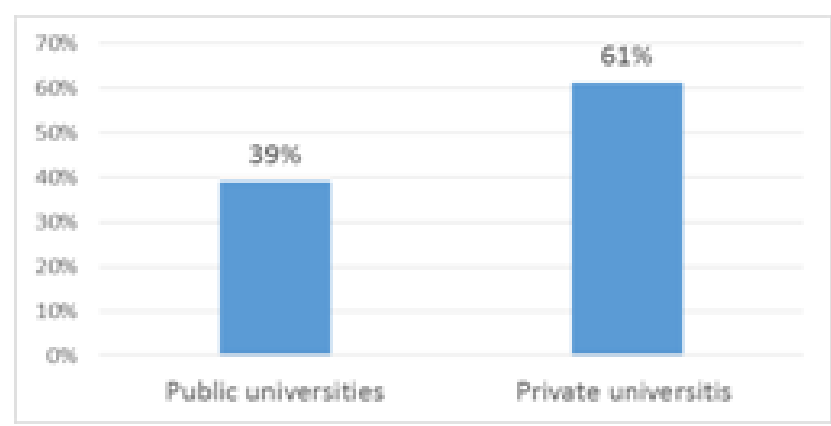

Figure 3: Adoption of cloud computing by educational institutions (private and public)

Table 6: Drivers and barriers for adopting cloud computing

\begin{tabular}{|l|r|l|c|}
\hline \multicolumn{2}{|l|}{ Drivers for adopting cloud computing } & \multicolumn{2}{|c|}{ Barriers to a dopting cloud computing } \\
\hline Enhanced availability & $30.5 \%$ & Privacy Concems & $67.3 \%$ \\
\hline Cost-effectiveness & $69.4 \%$ & Reliability & $34.8 \%$ \\
\hline Elasticity/ Scalability & $23.8 \%$ & Cloud Provider Lock-In & $45.5 \%$ \\
\hline Green environmental & $11.9 \%$ & $\begin{array}{l}\text { Geographic Location of Cloud } \\
\text { Provider Data Centres }\end{array}$ & $23.9 \%$ \\
\hline End-user Satisfaction & $16.4 \%$ & Security concems & $86.9 \%$ \\
\hline & $45.8 \%$ & $\begin{array}{l}\text { Regulatory Compliance } \\
\text { Concems }\end{array}$ & $33.4 \%$ \\
\hline Mobility & $26.0 \%$ & Lack of ability to customize & $15.7 \%$ \\
\hline Reduction in IT complexities & $18.0 \%$ & $\begin{array}{l}\text { Lack of Management } \\
\text { Understanding }\end{array}$ & $26.7 \%$ \\
\hline assets & $35.8 \%$ & Organizational Policies & $13.4 \%$ \\
\hline Bncreased interoperability & $38.4 \%$ & We did not have any concems & $5.0 \%$ \\
\hline
\end{tabular}


International Journal of Managing Information Technology (IJMIT) Vol.13, No.1, February 2021

However, $61 \%$ of those institutions $(43.9 \%)$ who have adopted cloud computing are private institutions, while only $39 \%$ are public, including UOB and BPT, as shown in Figure (3). The drivers and barriers for adopting cloud computing are demonstrated in Table (6). The results show that cost-effectiveness (69.4\%), mobility (45.8\%), and better collaboration across the team (38.4\%) were the most significant drivers for the universities to adopt cloud computing. However, the main inhibitors for adopting cloud computing were the security concerns $86.9 \%$; privacy concerns $67.3 \%$, and cloud computing lock-in (45.5\%). Only 5\% said they did not have any problems.

\subsection{Model Assessment}

To measuring the strength of the model, both its reliability and validity are assessed. For the reliability value, Cronbach's alpha was used. The reliability value of each dimension is demonstrated in Table (7), and all of the values were higher than 0.7. To assess the convergent validity, confirmatortoaevaluatewith Varimax rotation was used in order to assess the underlying structure of the research constructs' items. The loading of each factor should be greater than or equal to 0.5, and, as Tables (8) and (9) show, this has been achieved.

Table 7: Assessment of model measurement (Reliability)

\begin{tabular}{|l|c|c|}
\hline \multicolumn{1}{|c|}{ Variable } & N0. Items & Cronbach's Alpha \\
\hline Security & 4 & 0.788 \\
\hline Privacy & 5 & 0.876 \\
\hline Compatibility & 5 & 0.932 \\
\hline Vendor locking & 4 & 0.786 \\
\hline Relevant advantage & 4 & 0.765 \\
\hline Organization size & 4 & 0.893 \\
\hline Top management support & 5 & 0.833 \\
\hline Competitive pressure & 5 & 0.763 \\
\hline Digital teaching & 6 & 0.897 \\
\hline Digital research & 4 & 0.873 \\
\hline Organization Readiness & 5 & 0.789 \\
\hline
\end{tabular}

Table 8: Assessment of model measurement (validity)

\begin{tabular}{|c|c|c|c|c|c|c|c|c|}
\hline Variable & $\begin{array}{l}\text { Ite } \\
\mathrm{m}\end{array}$ & $\begin{array}{l}\text { Loadin } \\
\mathrm{g}\end{array}$ & Variable & Item & $\begin{array}{l}\text { Loadin } \\
\mathrm{g}\end{array}$ & Variable & Item & Loading \\
\hline \multirow{4}{*}{ Security } & PS1 & 0.783 & \multirow{5}{*}{$\begin{array}{c}\text { Compatibilit } \\
y\end{array}$} & CM3 & 0.781 & \multirow{4}{*}{$\begin{array}{c}\text { Relative } \\
\text { advantage }\end{array}$} & RA1 & 0.899 \\
\hline & PS2 & 0.673 & & CM2 & 0.884 & & RA2 & 0.767 \\
\hline & PS3 & 0.698 & & CM3 & 0.834 & & RA3 & 0.786 \\
\hline & PS2 & 0.688 & & CM4 & 0.789 & & RA4 & 0.873 \\
\hline \multirow{5}{*}{ Privacy } & PP1 & 0.882 & & CM5 & 0.798 & \multirow{5}{*}{$\begin{array}{c}\text { Organizatio } \\
\text { n size }\end{array}$} & OS1 & 0.883 \\
\hline & PP2 & 0.876 & \multirow{4}{*}{$\begin{array}{l}\text { Vendor } \\
\text { locking }\end{array}$} & VL1 & 0.673 & & OS2 & 0.893 \\
\hline & PP3 & 0.845 & & VL2 & 0.875 & & OS3 & 0.876 \\
\hline & PP4 & 0.789 & & VL3 & 0.769 & & OS4 & 0.838 \\
\hline & PP5 & 0.823 & & VL4 & 0.845 & & & \\
\hline
\end{tabular}


International Journal of Managing Information Technology (IJMIT) Vol.13, No.1, February 2021

Table 9: Assessment of model measurement (validity)-continuous

\begin{tabular}{|c|c|c|c|c|c|c|c|c|}
\hline Variable & Item & $\begin{array}{l}\text { Loadi } \\
\text { ng }\end{array}$ & Variable & Item & $\begin{array}{l}\text { Loadi } \\
\text { ng }\end{array}$ & Variable & Item & Loading \\
\hline \multirow{5}{*}{$\begin{array}{c}\text { Top } \\
\text { management } \\
\text { support }\end{array}$} & TP1 & 0.653 & \multirow{5}{*}{$\begin{array}{c}\text { Competitive } \\
\text { pressure }\end{array}$} & CP1 & 0.877 & \multirow{6}{*}{$\begin{array}{l}\text { Digital } \\
\text { teaching }\end{array}$} & DT2 & 0.691 \\
\hline & TP2 & 0.699 & & $\mathrm{CP} 2$ & 0.888 & & DT3 & 0.587 \\
\hline & TP3 & 0.762 & & CP3 & 0.863 & & DT4 & 0.701 \\
\hline & TP4 & 0.798 & & CP4 & 0.768 & & DT5 & 0.657 \\
\hline & TP5 & 0.656 & & CP5 & 0.873 & & DT6 & 0.581 \\
\hline \multirow{4}{*}{$\begin{array}{l}\text { Digital } \\
\text { research }\end{array}$} & DR1 & 0.567 & \multirow{4}{*}{$\begin{array}{c}\text { Organization } \\
\text { Readiness }\end{array}$} & OR1 & 0.782 & & OR5 & 0.632 \\
\hline & DR2 & 0.612 & & OR2 & 0.734 & \multirow{3}{*}{$\begin{array}{l}\text { Adoption } \\
\text { of cloud } \\
\text { computing }\end{array}$} & $\mathrm{AD} 1$ & 0.892 \\
\hline & DR3 & 0.674 & & OR3 & 0.768 & & $\mathrm{AD} 2$ & 0.834 \\
\hline & DR4 & 0.598 & & OR4 & 0.793 & & $\mathrm{AD} 3$ & 0.793 \\
\hline
\end{tabular}

\subsection{Model Testing}

To test the research model, regression analyses were conducted, the results of which are demonstrated in Table (10) and Table (11). The first regression analysis was performed to test the TOE factors' impact on the effective adoption of cloud computing as shown in Table (10). The results show that most of the TOE factors showed a significant effect on cloud computing adoption. For an instant, regarding the technological elements, relative advantage $(\beta=0.635$, $\mathrm{t}=15.73)$, security concerns $(\beta=0.325, \mathrm{t}=9.273)$, and privacy concerns $(\beta=0.314, \mathrm{t}=6.333)$ proved to have a strong to moderate impact on the adoption of cloud computing. However, compatibility and vendor lock-in ( $\beta=0.076, \mathrm{t}=1.546$ and $\beta=0.098, \mathrm{t}=1.132$ respectively) showed no significant effect on cloud computing adoption.

On the other hand, most of the organizational factors showed a positive effect on cloud computing adoption, such as organization readiness, top management support, and governance and policies $(\beta=0.537, \mathrm{t}=22.256, \beta=0.0 .345, \mathrm{t}=9.311$ and $\beta=0.171, \mathrm{t}=4.545$, respectively). However, organization size appeared not to affect cloud computing adoption as shown in Table (10). Finally, the environmental factors represented by the competitive pressure seemed to have a high impact on the adoption of cloud computing $(\beta=0.432, t=14.521)$. $\mathrm{R}$ square reveals that only $56 \%$ of the variance in cloud computing adoption is caused the TOE factors, as shown in Table (11).

Two other regressions were conducted to explore the impact of adopting cloud computing to build a digital educational environment (including digital research and digital learning and teaching, but excluding the digital campus). The results demonstrated that the adoption of cloud computing has a positive effect on building digital research $(\beta=0.387, \mathrm{t}=11.312)$ in which $45.7 \%$ of the variances in digital research explained by the adoption of cloud computing. In addition, the impact of adopting cloud computing on the digital learning and teaching was measured. The results demonstrated that cloud computing adoption had a strong positive effect on developing digital learning and teaching $(\beta=.625, \mathrm{t}=8.363)$, as shown in Table (10). The results also show that $67.3 \%$ of digital learning and teaching variance were caused by cloud computing adoption, as shown in Table (11). 
International Journal of Managing Information Technology (IJMIT) Vol.13, No.1, February 2021

Table 10: Model testing results

\begin{tabular}{|c|c|c|c|}
\hline Hypotheses & $b$ & $T$ & Status \\
\hline $\begin{array}{l}\text { H1: Relative advantage has a positive effect on the effective } \\
\text { adoption of cloud computing }\end{array}$ & 0.635 & 15.73 & Accepted \\
\hline $\begin{array}{l}\text { H2: Compatibility has a positive effect on the effective a doption of } \\
\text { cloud computing }\end{array}$ & 0.076 & 1.546 & Rejected \\
\hline $\begin{array}{l}\text { H3: Security has a positive effect on the effective adoption of cloud } \\
\text { computing }\end{array}$ & 0.325 & 9.273 & Accepted \\
\hline $\begin{array}{l}\text { H4: Privacy has a positive effect on the effective adoption of cloud } \\
\text { computing }\end{array}$ & 0.314 & 15.987 & Accepted \\
\hline $\begin{array}{l}\text { H5: Vendor lock-in has a positive effect on the effective a doption } \\
\text { of cloud computing }\end{array}$ & 0.098 & 1.132 & Rejected \\
\hline $\begin{array}{l}\text { H6: Organizational rea diness has a positive impact on the adoption } \\
\text { of effective cloud computing }\end{array}$ & 0.537 & 22.256 & Accepted \\
\hline $\begin{array}{l}\text { H7: Top management support has a positive impact on the adoption } \\
\text { of an effective cloud computing in Kingdom of Bahrain }\end{array}$ & 0.345 & 9.311 & Accepted \\
\hline $\begin{array}{l}\text { H8: Organizational size has a positive impact on the adoption of an } \\
\text { effective cloud computing in Kingdom of Bahrain }\end{array}$ & 0.081 & 0.968 & Rejected \\
\hline $\begin{array}{l}\text { H9: Govemance and policies has a positive effect in adopting an } \\
\text { effective cloud computing is educational institution }\end{array}$ & 0.171 & 6.543 & Accepted \\
\hline $\begin{array}{l}\text { H10: Govemance and policies has a positive effect in adopting an } \\
\text { effective cloud computing is educational institution }\end{array}$ & 0.432 & 14.521 & Accepted \\
\hline $\begin{array}{l}\text { H11: Adopting an effective Cloud computing has a positive impact } \\
\text { on building digital research environment in the Kingdom of } \\
\text { Bahrain }\end{array}$ & 0.312 & 11.321 & Accepted \\
\hline $\begin{array}{l}\text { H12: Adopting an effective Cloud computing has a positive impact } \\
\text { on building digital and leaming environment in the Kingdom of } \\
\text { Bahrain }\end{array}$ & 0.571 & 20.412 & Accepted \\
\hline
\end{tabular}

Table 11: Explanation of variances

\begin{tabular}{|l|l|}
\hline Variable & $\mathrm{R}^{2}$ \\
\hline Effective adoption of cloud computing & $56 \%$ \\
\hline Digital teaching and leaming & $67.3 \%$ \\
\hline Digital research & $4.7 \%$ \\
\hline
\end{tabular}

\section{DisCUSSION}

The findings show that there was high awareness of the importance of cloud computing among the educational institutions in the Kingdom of Bahrain and its perceived role in enhancing the competitive position of education in the region. The findings show that academics and administrative staff in the educational institutions were aware of cloud computing as most of them used cloud computing for educational and professional purposes. Besides, for personal purposes, they mostly used cloud computing in teaching, such as web hosting by academic staff in engineering and computing science and data storage (such as Dropbox and Drive) to share documents regarding assignments, projects, and other teaching documents. Administrators, on the other hand, used cloud computing for exchanging documents when communicating with the different management levels. UoB, for an instant, adopted the technical online call center, correspondence management systems (DocuTrack), and workflow model to simulate the organization processes on management transaction. 
Regardless of the noticeable and clear adoption on a personal level, the official level's adoption is still in its low stages. The findings revealed that only $43.9 \%$ of the educational institution adopted cloud computing, $39 \%$ of them were public universities. UoB integrated many of its processes on the cloud, such as Human Resources and the transaction exchange. AOU had most of its functions Online. The most drivers for this movement were cost-effectiveness, mobility, increasing interoperability, and better collaboration across teams. Information and Electronic Government-iGA announced that cloud computing's adoption has decreased the operation cost by $90 \%$. This reflects the country's vision 2030, which confirms that "the availability of cloud services offers the government an opportunity to deliver services more efficiently" [57]. Also, enhancing collaboration among students and academic staff are one concern for many educational institutions. Despite the critical role of cloud computing in higher education, the implementation of cloud computing in Bahrain's Kingdom confronts many problems and challenges. Many inhibitors discourage many universities from adopting cloud computing. Among these inhibitors are security and privacy concerns, followed by the cloud provider lock-in along with considerations on reliability and availability. For example, in Saudi Arabia, cloud computing services' availability was considered the major challenge factor is impacting the organization's decision whether to approve cloud computing or not [58]. In addition to the importance of secure services' security, cloud computing's high availability is vital for the education environment as it relies on these services. Accordingly, they should be available anytime from anywhere [58]. It is essential to pay attention to this issue since it is necessary to have access to the network to make cloud computing a feasible and desirable option.

The results suggest that most of the TOE factors have influenced the adoption of cloud computing. These factors were relative advantage, security, privacy, organizational readiness, top management support, governance and policies, and competitive pressure. See Table (10). However, compatibility, vendor lock-in, and organization size appeared not to impact the adoption of cloud computing in the Kingdom of Bahrain. The results confirm that the educational institutions recognize the relative advantage of cloud computing, which includes improving the quality of the teaching and learning processes, and are highly responsive to emergent technologies, increasing productivity, and providing new business opportunities [59]. This finding is consistent with similar studies reported in the literature [43].

Security and privacy have been identified as primary factors for cloud computing. Protection of data is a significant security issue for most of the educational institution. They may consider that their information is more secure if it is hosted within the institution. However, it will be at risk if they transfer essential and crucial data to a third party for hosting in a remote data centre, not under the institution's control [60]. There are many improvements in a privacy-enhancing technique, monitoring mechanisms, and encryption schemes to ensure confidentiality, integrity, and data security in the cloud environment [59].

Furthermore, several cloud computing providers nowadays guarantee that users' data will only be stored in specific countries [60]. These developments in the cloud should increase the demand for cloud computing in educational institutions. There is an opportunity for Gulf Cooperation Countries (Bahrain, Saudi Arabia, UAE, Kuwait, Oman, and Qatar, known as GCC) to develop unified policies and a framework to address potential cyber threats and weaknesses regardless of ICT solution [61]. It is expected that authorities will soon create some regulations and official standards on cloud computing and cloud security in the region, and related decisions about cloud models will be made soon as well [61]. These decisions will include hosting the data abroad and regulating data movement within and outside GCC countries [61]. 
Top management support is shown to be a predictor of cloud computing adoption. This finding is consistent with the literature suggesting that top management has a significant impact on cloud computing adoption because it can make the change and execute acceptance of cloud computing [24]. In educational institutions, the top management support can ensure the alignment of cloud computing services and the business needs and goals to provide the best cloud deployment for higher education settings. However, to allocate the necessary resources and financial support for the successful adoption of cloud computing, a well-established strategy need to be implemented to identify the business-value added for adopting such technology [22]. These results are governance and policies that are influential factors that can make the institution reluctant to move into cloud computing. IT standards, IT governance, and regulatory compliance are essential for supporting and providing sufficient resources for implementing cloud computing [47]moreover, organizational readiness. The final factor that was found to have an impact on cloud computing was competitive pressure. This was in line with what previous studies such as Low et al. [25] found, that competitive pressure pushed organizations in the high technology industry to adopt cloud computing more quickly.

Unexpectedly, however, in this study, compatibility was found not to be a facilitator for cloud computing in Bahrain's educational institutions. This can be because most of the educational institutions in the Kingdom of Bahrain do not consider the compatibility of their applications with the cloud environment as a problem and that there is no need for significant adjustments to shift to cloud computing [29][25]. The results were consistent with studies such as Low et al. [25] and Borgman et al. [62], both of which found that compatibility is not a major factor in implementing cloud computing. In parallel, organizational size is found to be a non-predictor of cloud computing adoption. These results are inconsistent with the literature suggesting that larger companies have resources to cover the cost and investment risk of an emerging technology [63]. Actually, in the Kingdom of Bahrain, big educational institutions (such as UoB) and medium ones (AOU and AU) and even small ones (Bahrain Institute for Public Administration - BIBF) have already adopted cloud computing. Chao [64] points out that organization size does not affect the willingness to adopt cloud computing, especially that the bigger the size, the more likely they are likely to suffer from failures.

Finally, Vendor lock-in had no significant effect on cloud computing adoption. Educational institutions had no concern about being hooked with a specific cloud provider. This is the case as many cloud providers have started offering their services through non-proprietary APIs, which are standards that support interoperability and allow cloud customers to move data and services from one provider to another without too much hassle [65]. Vendor lock-in is no longer a significant barrier to cloud computing adoption [22].

On the other hand, the adoption of cloud computing was shown to help in building a digital educational environment as it has a positive impact on building digital research and digital learning and teaching in the educational institution. Cloud computing affords opportunities for greater student choice in education. Cloud computing, because of its characteristics such as powerful computing and storage capability, fluid sharing, high reliability and safety, low cost, and high efficiency, has been increasingly applied in the teaching practice. Many teachers use cloud computing services to construct network courses, develop a collaborative learning environment, store teaching resources and make teacher-student interactions. Using an internetconnected device, students can access a wide array of resources and software tools that suit their learning styles and interests. Students can use office applications for free without purchasing, installing, and keeping these applications up to date on their computers. 
International Journal of Managing Information Technology (IJMIT) Vol.13, No.1, February 2021

Moreover, cloud computing helps allocate resource allocation to research activities such as equipment, software, hardware, attending conferences, and publishing in journals. The investment for research facilities is prioritized after that for teaching facilities. In many universities, teaching is considered the most essential and basic duty of their academic staff. For example, in most cases, the research budget counts no more than $10 \%$ of the total budget. Cloud computing can provide good opportunities for enhancing research in these universities. It will allow the collaboration and sharing of resources, which will provide more productive analysis more efficiently.

The educational institutions in the Kingdom of Bahrain need to enhance education development by utilizing emergent IT such as the software as service SaaS trend. It will improve the kind of resources used for education purposes, reduce the cost, ensure that green energy demand is met, enhance the security of the information, and facilitate the system's maintenance and operation. There is a need for gradual adoption of cloud services, recommended by starting with the most appropriate cloud computing systems. Email, e-learning systems, learning management systems are a good starting point for cloud adoption. Since cloud computing is a relatively new technology adopted in this country and specifically for educational institutions in the Kingdom of Bahrain, it requires some changes to be made in the policies of the Ministry of Higher Education and some governmental regulations to be taken by the Supreme Council of Information and Communication Technology (SCICT). Universities in the Kingdom of Bahrain need to improve data policies to protect their sensitive information, and this change can be introduced by the Higher Education Council (HEC). This involves developing institution-wide cloud policies to help the institutions select the right sourcing and solutions that comply with the regulations by the SCICT.

Finally, the decision-makers' awareness and correspondence are vital for adopting cloud computing [45]. Top leadership or management in the Kingdom of Bahrain's educational institutions needs to adopt more digital strategic planning to drive the change from traditional deployment to cloud adoption, which aligns with what cloud services are needed for and what type of cloud deployment is best for higher education settings. Before all of that, a digital culture needs to be enforced to ensure top management support. Competitive pressure is implementing universities in Bahrain's Kingdom to adopt the emergent technology as they are facing very intensive and fierce competition. Most private universities have the same size and provide almost the same disciplines or specializations, emphasizing the need to differentiate their service and offer a unique learning environment to gain and sustain their competitive advantage.

\section{CONClusion}

This study's goal has been to examine the factors affecting the adoption of cloud computing in educational institutions and its impact on building a digital educational environment in the Kingdom of Bahrain. This has been done by using a cause-effect model. The causal side considered the factors that affected the adoption of cloud computing. The effect side combines the innovation characteristics of cloud computing and the TOE (technology, organization, and environment) perspectives of the institution. The findings have shown a high awareness of adopting cloud computing to provide a more efficient and effective learning environment. Although there are many drivers for adopting cloud computing, such as cost-effectiveness, scalability, or enhancement of collaboration and connectivity, educational institutions have adopted cloud computing to build a digital educational environment. This environment can cover digital campus, digital learning and teaching, and digital research. The study is one of the few studies that tackle cloud computing adoption in the Arab context, especially the Arabian Gulf countries. The study can be used as guidelines for the top management in the education sector to 
International Journal of Managing Information Technology (IJMIT) Vol.13, No.1, February 2021

accelerate cloud computing implementation to facilitate the shift from the present learning systems to cloud-based ones. This study stresses that cloud computing can help build a digital educational environment in the Kingdom of Bahrain.

\section{REFERENCES}

[1] Chang, V.; Walters, R. and Wills, G. (2014) Review of Cloud Computing and existing Frameworks for Cloud adoption. In Advances in Cloud Computing Research. NOVA Publishers.

[2] Peter, M. and Timothy, G. (2011), The NIST Definition of Cloud Computing, September 2011. (Retrieved Feb 2018). Available Online on: http://csrc.nist.gov/publications/nistpubs/800145/SP800- 145.pdf

[3] Alshamaila, Y.; Savvas, P. and Feng, L., (2013) 'Cloud computing adoption by SMEs in the northeast of England: A multi-perspective framework', Journal of Enterprise Information Management, Vol. 26 No. 3, pp. 250-275, Online on: https://doi.org/10.1108/17410391311325225.

[4] Astri, L. (2015) 'A Study Literature of Critical Success Factors of Cloud Computing in Organizations'. International Conference on Computer Science and Computational Intelligence (ICCSCI 2015). Online on: www.sciencedirect.com.

[5] Marinescu, Dan C. (2018) Cloud Computing: Theory and Practice. Elsevier Inc., 2nd Edition.

[6] Bittman, T. (2009) Cloud Computing Inquiries at Gartner. Online on: https://blogs.gartner.com/thomas_bittman/2009/10/29/cloud-computing-inquiries-at-gartner/

[7] Ercan, T. (2010) 'Effective use of cloud computing in educational institutions', Procedia Social and Behavioral Sciences, Vol. 2, pp. 938-942.

[8] Dong, B.; Zheng, Q.; Qiao, M.; Shu, J. and Yang, J. (2009) 'BlueSky Cloud Framework: An ELearning Framework Embracing Cloud Computing', In: Proceedings of the 1st International Conference on Cloud Computing (CloudCom '09), Springer-Verlag, Berlin, Heidelberg, pp.577-582.

[9] Madan, D., Pant, A., Kumar, S. and Arora, A. (2012) 'E-learning based on Cloud Computing', International Journal of Advanced Research in Computer Science and Software Engineering, Vol. 2, No. 2, pp. 45-51.

[10] Muhammad, A. and Abdulrahman, S. (2015) 'Cloud Computing Based e-Learning: Opportunities and Challenges for Tertiary Institutions in Nigeria', International Journal of e-Education, e-Business, eManagement and e-Learning, Vol. 5, No. 3, pp. 144-152.

[11] Castro Sanchez, J. and Aleman, E. (2011) 'Teachers' opinion survey on the use of ICT tools to support attendance-based teaching', Computers \& Education, Vol. 56, No. 3, pp. 911-915. Elsevier Ltd.

[12] Raihi, G. (2015), 'E-learning Systems Based on Cloud Computing: A Review', Procedia Computer Science, Vol. 62. PP. 352-359

[13] Anjali, J. and Pandey, U. (2013) 'Role of Cloud Computing in Higher Education', International Journal of Advanced Research in Computer Science and Software Engineering, Vol 3, No 7, pp. 966972

[14] DT News (2017, June 15) Bahrain moves to cloud computing. DT News Network. Retrieved Online on:: http://www.newsofbahrain.com/viewNews.php?ppId=34482\&pid=21\&MNU

[15] Carlson, T. (2017) The future of cloud computing in Bahrain. DT News Network. Online on: http://www.newsofbahrain.com/viewNews.php?ppId=29822\&TYPE=Posts\&pid=21\&MNU=2\&SUB $=4$.

[16] Higher Education Council (2014) 'National Higher Education Strategy (2014-2024): Putting Higher Education in the Heart of the Nation'. Online on: http://www.moedu.gov.bh/hec/UploadFiles/Bahrain\%20Higher\%20Education\%20Strategy\%20\%20Summary.pdf

[17] Thorsteinsson, G.; PAGE, T. and Niculescu, A. (2010) 'Using Virtual Reality for Developing Design Communication', Studies in Informatics and Control, ISSN 1220-1766, Vol. 19, No. 1, pp. 93-106

[18] Chapman, S. (2018) 'How the University of Bahrain is technologically tailoring its campus?', Gigabit Magazine. Online on: http://www.gigabitmagazine.com/company/how-university-bahraintechnologically-tailoring-its-campus\#

[19] Fernández A. and Peralta D. (2014) 'E-learning and educational data mining in cloud computing: an overview', International Journal of Learning Technology, Vol. 9, No. 1. PP. 25-52. 
International Journal of Managing Information Technology (IJMIT) Vol.13, No.1, February 2021

[20] Britto, M. (2011) 'An Overview of Cloud Computing in Higher Education'. In C. Ho \& M. Lin (Eds.), In Proceedings of E-Learn 2011--World Conference on E-Learning in Corporate, Government, Healthcare, and Higher Education, pp. 1062-1071, Honolulu, Hawaii, USA

[21] Rogers, E.M. (2003), Diffusion of Innovations, 5th ed., Free Press, New York, 2003.

[22] Tashkandi, A. and Al-Jabri, I. (2015), 'Cloud computing adoption by higher education institutions in Saudi Arabia: An exploratory study', Cluster Computer, Vol. 18, pp. 1527-1537

[23] Alhammadi, A.; Stanier, C. and Eardley, A. (2015) 'The determinants of cloud computing adoption in Saudi Arabia', Computer science and information Technology (CS\&IT), pp. 55-67, David C. Wyld et al (Eds): CSEN, AISO, NCWC, SIPR

[23] Alkhater, N.; Wills, G. and Walters, R. (2014) 'Factors influencing an organization's intention to adopt cloud computing in Saudi Arabia', IEEE 6th International Conference on Cloud Computing Technology and Science, pp. 1040-1044.

[25] Low, C.; Chen, Y. and Wu, M. (2011) 'Understanding the determinants of cloud computing adoption', Industrial Management \& Data Systems, Vol. 111 No. 7, pp. 1006-1023

[26] Buyya, R.; Yeo, C.; Venugopal, S.; Broberg, J. and Brandic, I. (2009) 'Cloud computing and emerging IT platforms: Vision, hype, and reality for delivering computing as the 5th utility', Future Generation Computer Systems, Vol. 26, No. 6, pp.599-616.

[27] Stieningera, M.; Nedbala, D.; Wetzlingera, W.; Wagnera, G. and Erskineb, M. (2014), 'Impacts on the organizational adoption of cloud computing: A reconceptualization of influencing factors', in proceeding of the Conference on ENTERprise Information Systems / ProjMAN 2014 - International Conference on Project MANagement / HCIST 2014 - International Conference on Health and Social Care Information Systems and Technologies-CENTERS 2014

[28] Kauffman, R.; Dan, M.; and YU, M. (2016) 'Metrics Suite of Cloud Computing Adoption Readiness', Electronic Markets. PP. 1-27. Research Collection School of Information Systems. Available at: http://ink.library.smu.edu.sg/sis_research/3158

[29] Kiriinya, d. (2014) Factors influencing cloud computing adoption in organizations: a case of cooperative insurance company of Kenya, unpublished MSc dissertation United States International University, USA

[30] Almubarak, S. (2017) 'Factors Influencing the Adoption of Cloud Computing by Saudi University Hospitals', (IJACSA) International Journal of Advanced Computer Science and Applications, Vol. 8, No. 1

[31] Rahimah, K. and Aziati, N. (2017), 'The Integrated Framework of Cloud Computing Implementation in Higher Education Institution: A Review of Literature', Advanced Science Letters, Vol. 23, pp. 1475-1479

[32] Almajalid, R. A Survey on the Adoption of Cloud Computing in Education Sector, Online on: on: on: on: on:: "https://arxiv.org/ftp/arxiv/papers/1706/1706.01136.pdf

[33] Cheng, F. and Lai, W. (2012) 'The impact of cloud computing technology on legal infrastructure within internet- Focusing on the protection of information privacy', Procedia Engineering, Vol. 29, 0, pp. 241-251

[34] Svantesson, D. and Clarke, R. (2010), 'Privacy and consumer risks in cloud computing', Computer Law \& Security Review, Vol. 26, No. 4, pp. 391-397.

[35] Hoffman, D.; Novak, T. and Peralta, M. (1999) 'Information privacy in the marketspace: Implications for the commercial uses of anonymity on the web', Information Society, Vol. 15, No. 2, pp.129-139.

[36] Briscoe, G. and Marinos, A. (2009) 'Digital ecosystems in the clouds: towards community cloud computing'. In: IEEE, (corp. ed.) 2009 3rd IEEE International Conference on Digital Ecosystems and Technologies (DEST 2009). Institute of Opara-MartinsOpara-MartinsOpara-MartinsElectrical and Electronics Engineers (IEEE), New York, USA, pp. 103-108.

[39] Kamel, M. (2015) Vendor Lock-in in the transition to a Cloud Computing platform, KTH royal institute of Technology, Degree in Information and Communication Technology, Stockholm, Sweden 2015

[38] Sultan, N. (2011), 'Reaching for the "cloud": How SMEs can manage', International Journal of Information Management, Vol. 31, No. 3, pp. 272-278.

[40] Burd, S. (2015) Systems architecture: Hardware and software in business information systems (6th ed.), Boston, MA: Course Technology, Cengage Learning 
International Journal of Managing Information Technology (IJMIT) Vol.13, No.1, February 2021

[41] Ramdani, B.; Chevers, D. and Williams, D. (2013), 'SMEs\&apos; adoption of enterprise applications: A technology-organization-environment model', Journal of Small Business Enterprise Development, Vol. 20, No. 4, pp. 735-753

[42] Oliveira, T. and Martins, M. (2010), 'Understanding e-business adoption across industries in European countries', Industrial Management \& Data Systems, Vol. 110, pp. 1337-1354.

[43] Pan, M. and Jang, W. (2008) 'Determinants of the adoption of enterprise resource planning within the technology-organization-environment framework: Taiwan's communications industry', Journal of Computer Information Systems, Vol. 48, pp. 94-102.

[44] Wang, Y., Wang, Y. and Yang, Y. (2010), 'Understanding the determinants of RFID adoption in the manufacturing industry', Technological Forecasting and Social Change, Vol. 77, pp. 803-15.

[45] Abdollahzadehgan, A.; Hussin, C.; Razak, A.; Gohary, M. and Amini, M. (2013) 'The Organizational Critical Success Factors for Adopting Cloud Computing in SMEs', Journal of Information Systems Research and Innovation (JISRI), Vol. 4, No. 1, pp: 67-74. Online on: on: on: on: on:: SSRN: https://ssrn.com/abstract=2333028

[46] Alyssa, M.; Alharthi, A.; Robert J. Walters, R., and Wills, G. (2017) 'A framework for critical security factors that influence the decision of cloud adoption by Saudi government agencies', Telematics and Informatics, Vol. 34, No 7, November, pp. 996-1010

[47] Aboelmaged, M. (2014) 'Predicting e-readiness at firm-level: An analysis of technological, organizational and environmental (TOE) effects on e-maintenance readiness in manufacturing firms', International Journal of Information Management, Vol. 34, No. 5, pp. 639-651, Oct. 2014.

[48] Khan, N. and Al-Yasiri, A. (2015) 'Framework for cloud computing adoption: a roadmap for SMSs to cloud migration”, International Journal on Cloud Computing: Services and Architecture (IJCCSA), Vol. 5, No. 5/6, December 2015

[49] Azman, R.; Daud, M. and Aziati, N. (2014) 'The key drivers of cloud technology implementation in education management system', in Proceeding of Technology and Innovation (TECHON 2014) Kuching, Sarawak

[50] Huang, L. and Liu, C. (2013) 'Construction of collaborative learning environment supported by cloud computing', in proceeding of the 2nd International Conference on Computer Science and Electronic Engineering (ICCSEE2013), Paris, France

[51] Kumar, B.; Kommareddy, S. and Rani, N. (2013) 'Effective ways cloud computing can contribute to education success', Advanced Computing: An International Journal (ACIJ), Vol.4, No.4, July 2013

[52] Devasena, C. (2014) 'Impact study of cloud computing on business development', Operations Research and Applications: An International Journal (ORAJ), Vol. 1, No.1, August 2014

[53] Marston, S.; Li, Z.; Bandyopadhyay, S.; Zhang, J., and Ghalsasi, A. (2011, April) 'Cloud computing — The business perspective', Decision Support Systems, Vol. 51, No. 1, pp. 176-189.

[54] Bottum, J.; Atkins, D.; Black, A.; McMullen, R.; Tannenbaum, T.; Cheetham, J.; Wilgenbusch, J.; Bhatia, K.; Deumens, E.; Olsen, B.; Fox, G.; Ziolkowski, M.; Bedrossian, A. and Fay, D. (2017) 'The Future of Cloud for Academic Research Computing', Results of an NSF-Supported Workshop, Entitled "Cloud Forward” Supported by NSF ACI/CSE Award 1632037, Final report,

[55] Lakshminarayanan, R.; Kumar, B. and Raju, M. (2014) 'Cloud Computing Benefits for Educational Institutions', Information Security and Computer Fraud, Vol. 2, No. 1, pp. 5-9, 2014

[56] Alshuwaier, F., Alshwaier, A., AND Areshey, A. (2012) 'Applications of cloud computing in education', 8th International Conference on Computing and Networking Technology (INC, ICCNT and ICMIC), Gyeongju, 2012, pp. 26-33.

[57] Sugumaran, H. and Al-Mutawa, K., Bahrain Cloud Transformation: Cloud First in eGovernment (2017), 20 December 2018, online on: http://www.iga.gov.bh

[58] Ashtari, S. and Eydgahi, A. (2015) 'Student Perceptions of Cloud Computing Effectiveness in Higher Education', in proceeding of the 2015 IEEE 18th International Conference on Computational Science and Engineering, pp. 184-191

[59] Oliveira, T.; Thomas, M.; Espadanal, M. (2014) 'Assessing the determinants of cloud computing adoption: An analysis of the manufacturing and services sectors', Information and Management, Vol. 51, pp. 497-510

[60] Ahmed, Z. Ghareb, M., Jaafar, A. (2017) 'The Ability of implementing Cloud Computing in Higher Education - KRG', Kurdistan Journal of Applied Research (KJAR), Vol. 2, No. 1, June

[61] IISS (2013) 'Considerations for regulatory and policy approaches to cloud computing in the GCC', IISS White Paper 
International Journal of Managing Information Technology (IJMIT) Vol.13, No.1, February 2021

[62] Borgman, H.; Bahli, B.; Heier, H. and Schewski, (2013) 'Exploring cloud computing adoption and governance with the TOE framework', 46th Hawaii International Conference on System Sciences (HICSS), IEEE, pp. 4425-4435.

[63] Chong, A. and Chan, A. (2012) 'Structural equation modelling for multi-stage analysis on radio frequency identification (RFID) diffusion in the health care industry', Expert System. Appl. Vol. 39, pp. 8645-8654.

[64] Chao, G.; Peng, A. Dutta, and Choudhary, A. (2014) 'Exploring Critical Risks Associated with Enterprise Cloud Computing', in CloudComp, Vol. 133, V. C. M. Leung and M. Chen, Eds. Cham: Springer International Publishing, 2014, pp. 132-141.

[65] Muehlen, M.; Nickerson, J.; and Swenson, K. (2005) 'Developing web services choreography standards-the case of REST vs SOAP', Decision Support Systems, Vol. 40, No. 1, pp. 9-29

\section{AUTHORS}

Jaflah Hassan Al-Ammary is the assistant professor in the Department of Information Systems in the College of IT at the University of Bahrain. She holds PhD from the University of Murdoch (Australia). Al-Ammary's research interest focuses on IS strategies and Applications focus more on Strategic alignment, Knowledge Management, and educational technology and E-learning. Al-Ammary has many publications on KM-strategic alignment and the strategic role of the Information systems and SISP at the organization of Bahrain.

Dr. Saleh holds a PhD in Information, and a M.Sc. in Telecommunication Systems from DePaul University in Chicago, IL. His main research interests are in information security, wireless data communication, and eLearning.
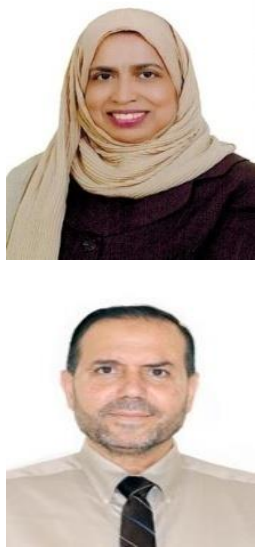